\title{
Hematemesis With Gastric Laceration After Tattooing a Polyp With Purified Carbon: A Review of the Literature
}

\author{
Ana Isabel Gonzalez-Tallon ${ }^{\mathrm{a}, \mathrm{b}}$, Miguel Rivero-Fernandez ${ }^{\mathrm{a}}$, Irina Calvo-Ramos ${ }^{\mathrm{a}}$, \\ Antonio Diaz-Sanchez ${ }^{\mathrm{a}}$, Maria del Rosario Gonzalez-Alonso ${ }^{\mathrm{a}}$, Elsa De la Fuente-Briongos ${ }^{\mathrm{a}}$, \\ Rebeba Manzano-Fernandez ${ }^{\text {a }}$ Eloisa Moya-Valverde ${ }^{a}$, Jose Maria Riesco-Lopez ${ }^{a}$, \\ Rocio Campos-Cantero ${ }^{\mathrm{a}}$
}

\begin{abstract}
Endoscopic tattooing is a simple and effective technique for marking small lesions, so they can be localized during surgery or in later endoscopies. Various agents can be used such as India ink or a solution of purified carbon particles. The number of complications from tattooing is relatively small, but not rare. The majority of the literature on the subject refers to complications in the colon. We present a case of gastric bleeding secondary to a laceration following tattooing with purified carbon, and a literature review.
\end{abstract}

Keywords: Tattoo; Purified carbon; India ink; Complication; Laceration; Hematemesis

\section{Introduction}

Certain endoscopic lesions will require to be marked in order to be found at a later stage, either during surgery or at posterior endoscopies. Some techniques are available for that purpose, such as radiological tests, the placement of clips, intraoperative endoscopy, or tattooing. The latter is widely used, as different substances can be applied and has a low complication rate in general [1-3].

Most of the complications that have been reported in the literature are described in the colon. We present a case of a patient with gastric bleeding secondary to a laceration following tattooing with purified carbon.

\section{Case Report}

The patient was a 68 -year-old male with a past medical history

Manuscript accepted for publication January 18, 2017

aDepartment of Gastroenterology, Hospital Universitario del Sureste, Arganda del Rey, Madrid, Spain

${ }^{b}$ Corresponding Author: Ana Isabel Gonzalez-Tallon, Department of Gastroenterology, Hospital Universitario del Sureste, Arganda del Rey, Madrid, Spain.Email: aigleztallon@gmail.com

doi: https://doi.org/10.14740/gr728w of diabetes, hypertension, dyslipidemia and ischemic heart disease, for which he required the placement of three stents 2 years before the current episode. His current treatment included antiplatelet therapy with acetylsalicylic acid.

The patient was under gastroenterology follow-up for a mucosal lesion in the gastric antrum, $1.3 \times 20 \mathrm{~mm}$ in size, detected at a gastroscopy. An endoscopic ultrasonography (EUS) was also performed, but was not conclusive. Therefore, the patient underwent an endoscopic mucosectomy and histopathology was consistent with an inflammatory fibroid polyp.

Nine months later, a second mucosectomy was performed due to the recurrence of the polyp, presenting the same histological findings. One year after that, the lesion recurred for the third time, and decision was made to treat the lesion surgically.

Prior to surgery, a gastroscopy was performed to tattoo the polyp. Antiplatelet therapy was withheld 7 days prior to the procedure. A total of $4 \mathrm{~mL}$ of sterile solution of highly purified carbon particles was injected into the submucosa sorrounding the lesion at several different spots (upper and lower quadrants proximal to the polyp $0.5-1 \mathrm{~mL}$ per injection). During the injection, no resistante was found. There were no immediate complications during the procedure.

The patient was discharged, but presented to the emergency room (ER) $4 \mathrm{~h}$ later with sudden epigastric pain and hematemesis. On arrival, the patient was hemodinamically stable and on examination, the epigastric area was tender, but without evidence of peritoneal irritation. Laboratory workup results were as follows: leukocytes $7.450 \times 10^{3} / \mu \mathrm{L}$ (neutrophils $82 \%$ ), hemoglobin $13.5 \mathrm{~g} / \mathrm{dL}$, platelets $148,000 / \mu \mathrm{L}$ and a prothrombin time $14.2 \mathrm{~s}$.

An urgent gastroscopy was performed, revealing a submucosal extension of the dye from the antrum towards the gastric body. In that area, a deep laceration in the gastric wall was found, measuring several centimeters and oozing blood (Fig. 1). Several injections of a diluted solution of adrenaline $(1: 10,000)$ were performed to stop the bleeding. However, given the size of the laceration, it could not be closed with hemoclips.

The patient was admitted on intravenous fluids and empiric antibiotic therapy. He was kept nil by mouth. An emergency computed tomography $(\mathrm{CT})$ scan was also performed to exclude gastric perforation.

The CT scan revealed thickening of the stomach wall, compatible with an intramural hematoma and related inflammatory response, but no pneumoperitoneum, free fluid, or col- 

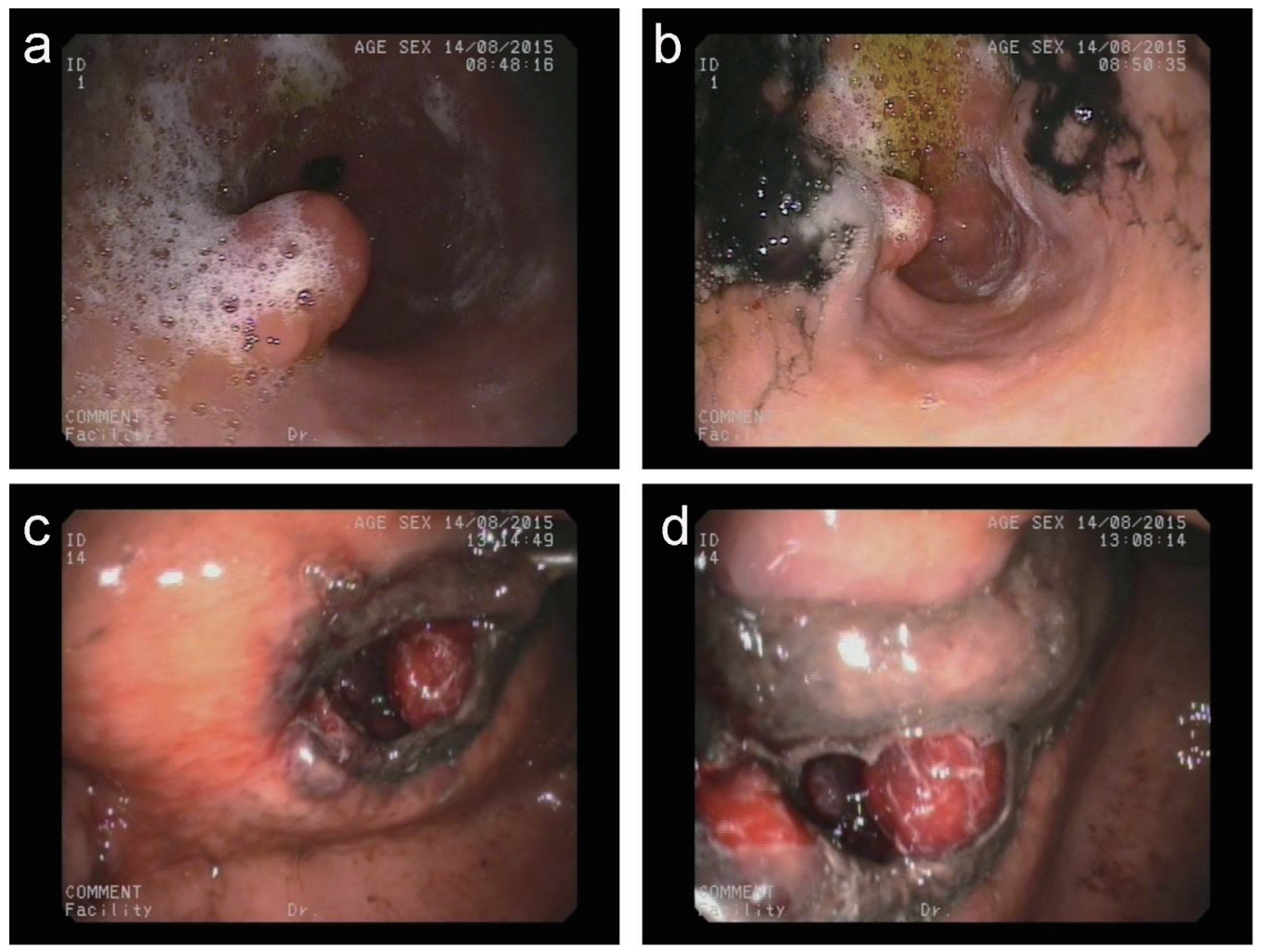

Figure 1. (a) Gastric polyp. (b) Tattooed gastric polyp. (c, d) Laceration after tattooing.

lections were seen.

Over the 7-day admission, the patient evolved favorably, with no recurrence of bleeding and oral diet could be restarted with no further complications.

A follow-up CT scan was performed and showed a normal gastric wall. Three months later, the patient underwent surgical resection of the fibroid polyp, wich was located by intraoperative gastroscopy. The patient was discharged after surgery and is currently asymptomatic. The 6-month postoperative gastroscopy also showed no evidence of polyp recurrence.

\section{Discussion}

Identifying intestinal lesions during surgery is often difficult, particularly with laparoscopic surgery. Since palpation is not possible, small lesions, such as polyps, vascular lesions, or diverticula, may go unnoticed $[1,2]$. To facilitate localization, different techniques are used, such as radiological tests, intraoperative endoscopy, clips or tattooing. The latter is longlasting and effective, so it is widely used [3].

Tattooing as a method of marking the base of a polyp was first described in 1958 [4]. The use of this technique to locate colonic lesions during surgery was first described in 1975 [5]. Ever since, different tattooing agents have been tested, such as indocyanine green, methylene blue, indigo carmine, India ink, or solutions of highly purified carbon particles (SPOT ${ }^{\mathrm{TM}}$ ). The latter two are the most commonly used today because they remain visible 3 - 12 months after tattooing in $68-88 \%$ of pa- tients $[6,7]$. Other agents such as indocyanine green, are visible for only 3 - 8 days [8,9], while methylene blue remains for 7 days. If the surgery is performed outside of these time frames, it is possible that the marker will not be identifiable. As a result, these agents are less frequently used [10, 11].

Various case series have proven the safety and efficacy of these agents to mark lesions in the gastrointestinal tract. None of them reported complications (Table 1) [1, 7-9, 11-19]. Most of the avalilable studies involve the colon, but there are also some studies showing safety and efficacy of tattooing techniques in other parts of the gastrointestinal tract, such as the esophagus and the stomach [15, 16, 20-22]. Likewise, India ink appears safe when used in children [23].

However, India ink needs to be diluted and sterilized before use [24], unlike highly purified carbon particles, which are dispensed ready-to-use. Highly purified carbon has proven to be safe and effective, with a low rate of complications [17-19] and in many cases, it is preferred over India ink.

The number of complications from tattooing with India ink or highly purified carbon is relatively small, but not rare. Most complications are secondary to transmural injections spreading the dye to the submucosa, peritoneum, or pericolic adipose tissue [25-29]. Most cases are asymptomatic. Nevertheless, there have been reports of intracavitary and abdominal wall abscesses [30-32], focal peritonitis [33, 34], hematoma [35], inflammatory pseudotumor formation [36, 37], idiopathic inflammatory bowel disease [38], simulated intestinal infarction [39], intestinal perforation [40], and mesenteric air embolism [41]. A compilation of the aforementioned complications 
Table 1. Summary of Efficacy Studies on Dyes

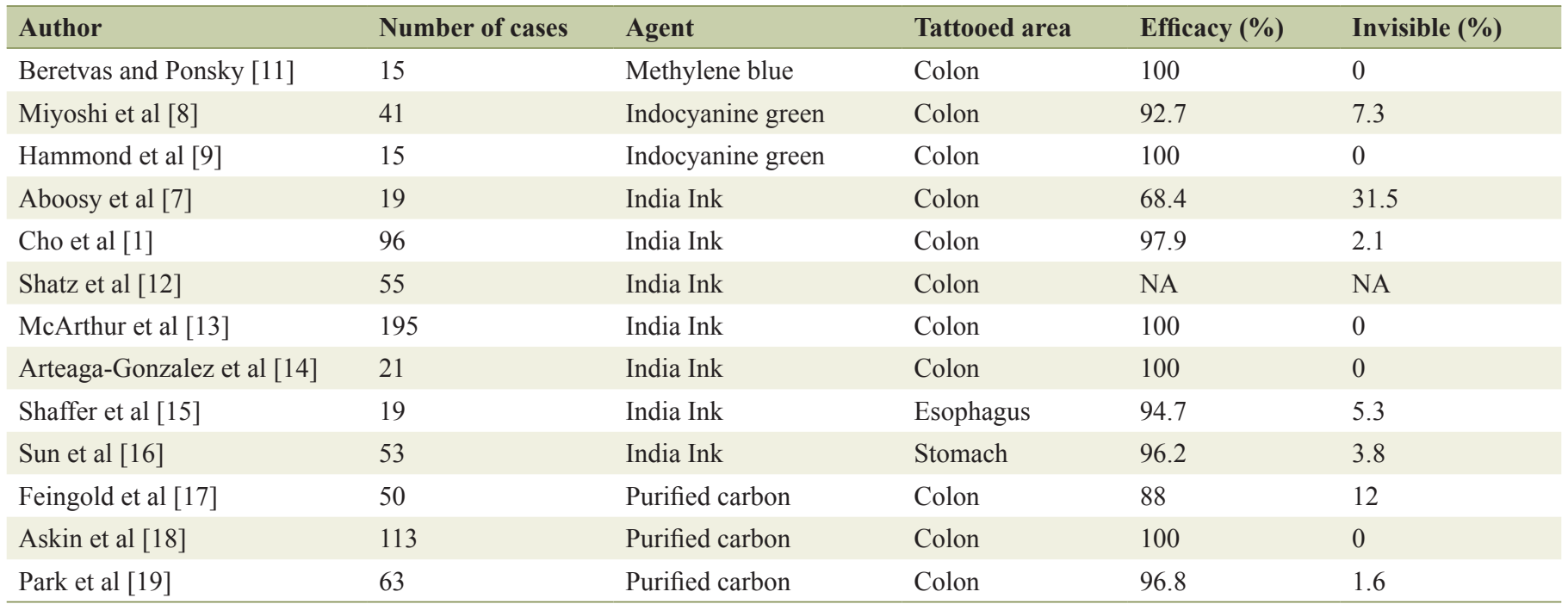

NA: not available.

is shown in Table 2 [25-41].

Most of the complications reported in the literature refer to the colon and the small intestine. Our case report, however, relates to a gastric complication. The patient underwent multiple prior mucosal resections, and the subsequent wall fibrosis could have been the cause of the complication. Despite the fact that inflammatory fibroid polyps tend to have dilated and abnormal vessels, tattooing is usually performed on the surrounding healthy gastric wall, so it does not seem probable that the laceration could have been a consequence of vascular disruption by the needle, although it cannot be completely excluded as a cause. Purified carbon is not a biologically inert substance, and given the location and characteristics of the laceration, a chemical reaction with the compounds in the dye could have also played a role.

In conclusion, endoscopic tattooing is a very useful tool for the surgical localization of digestive tract lesions. India ink has been used for several decades with a good safety profile

Table 2. Summary of Complications From the Endoscopic Tattooing Described Above

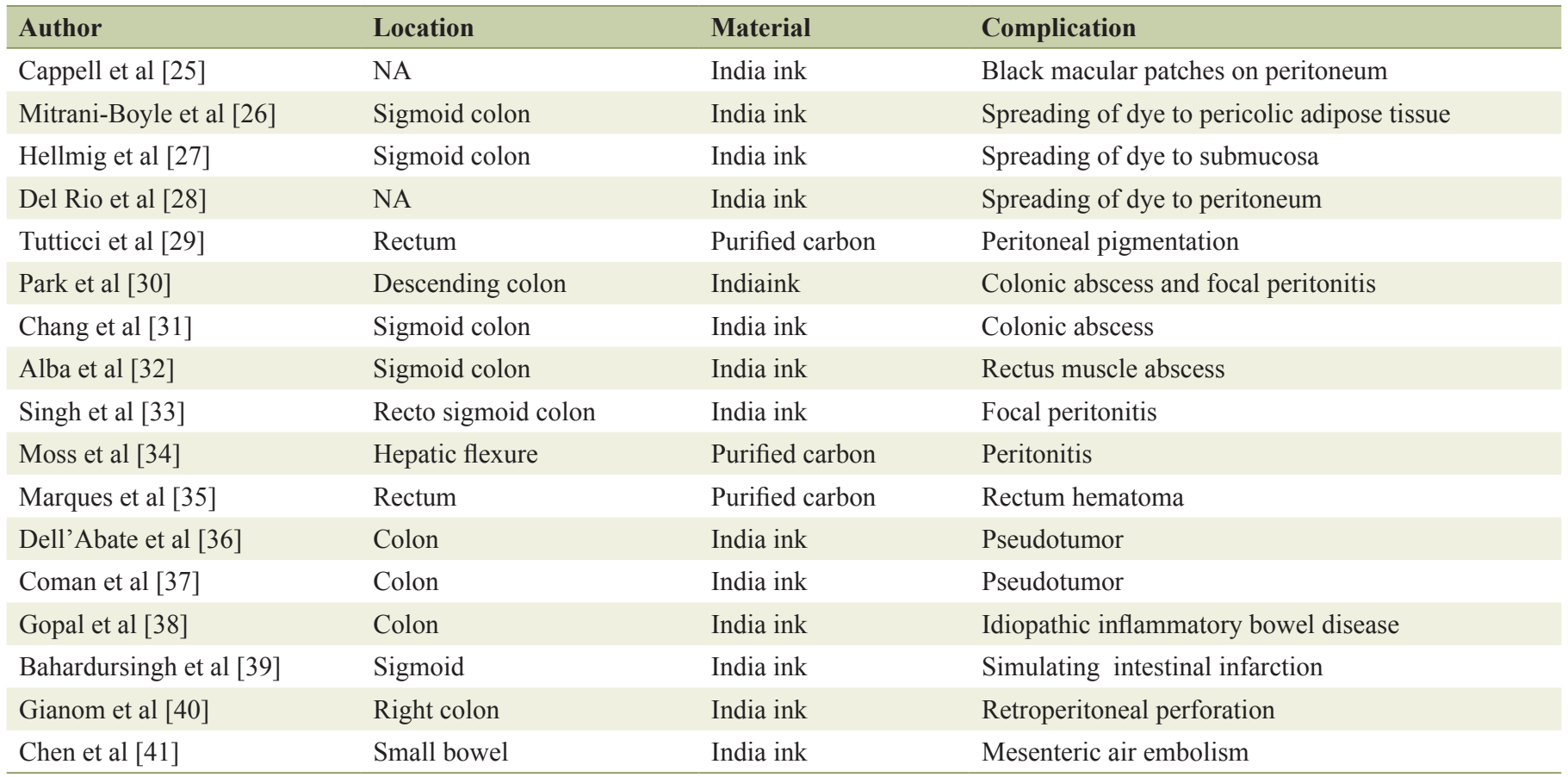

NA: not available. 
and the commercial availability of ready-to-use sterile preparations (SPOT ${ }^{\mathrm{TM}}$ ) has led to a wider use of endoscopic tattooing. However, the long-term safety and efficacy data for these compound are limited. The mechanism by which the reported complications have arisen is not currently known. One posibility could be extra-enteric bacterial inoculation through the injection needle, but if we consider that carbon particles are not biologically inert, development of chemical reactions producing damage cannot be ruled out. Further evaluation is needed to compare the different known agents used in such injections, as well as comparison with other marking techniques now in use, such as clips or radiological tests.

\section{Conflicts of Interest}

All the authors declare that they have no conclicts of interest.

\section{Author Contributions}

This study was designed and coordinated by GTAI as the principal investigator. RLJM, CRI, FBE and CCR provided conceptual and technical guidance for all aspects of the project. DSA, RFM, MFE, MVE and GAMR contributed in the clinical and technical aspects of the study. The manuscript was written by GTAI, commented and approved by all authors.

\section{References}

1. Cho YB, Lee WY, Yun HR, Lee WS, Yun SH, Chun HK. Tumor localization for laparoscopic colorectal surgery. World J Surg. 2007;31(7):1491-1495.

2. Ghahremanlou R, Bulut O, Jess P. [Localization of colonic tumor in laparoscopic surgery. Intraoperative colonoscopy or preoperative tattoo]. Ugeskr Laeger. 2005;167(32):2886-2889.

3. Ellis KK, Fennerty MB. Marking and identifying colon lesions. Tattoos, clips, and radiology in imaging the colon. Gastrointest Endosc Clin N Am. 1997;7(3):401-411.

4. Trakarnsanga A, Akaraviputh T. Endoscopic tattooing of colorectal lesions: Is it a risk-free procedure? World J Gastrointest Endosc. 2011;3(12):256-260.

5. Ponsky JL, King JF. Endoscopic marking of colonic lesions. Gastrointest Endosc. 1975;22(1):42-43.

6. Kethu SR, Banerjee S, Desilets D, Diehl DL, Farraye FA, Kaul V, Kwon RS, et al. Endoscopic tattooing. Gastrointest Endosc. 2010;72(4):681-685.

7. Aboosy N, Mulder CJ, Berends FJ, Meijer JW, Sorge AA. Endoscopic tattoo of the colon might be standardized to locate tumors intraoperatively. Rom J Gastroenterol. 2005;14(3):245-248.

8. Miyoshi N, Ohue M, Noura S, Yano M, Sasaki Y, Kishi K, Yamada T, et al. Surgical usefulness of indocyanine green as an alternative to India ink for endoscopic marking. Surg Endosc. 2009;23(2):347-351.

9. Hammond DC, Lane FR, Mackeigan JM, Passinault WJ.
Endoscopic tattooing of the colon: clinical experience. Am Surg. 1993;59(3):205-210.

10. Lane KL, Vallera R, Washington K, Gottfried MR. Endoscopic tattoo agents in the colon. Tissue responses and clinical implications. Am J Surg Pathol. 1996;20(10):12661270.

11. Beretvas RI, Ponsky J. Endoscopic marking: an adjunct to laparoscopic gastrointestinal surgery. Surg Endosc. 2001;15(10):1202-1203.

12. Shatz BA, Weinstock LB, Swanson PE, Thyssen EP. Long-term safety of India ink tattoos in the colon. Gastrointest Endosc. 1997;45(2):153-156.

13. McArthur CS, Roayaie S, Waye JD. Safety of preoperation endoscopic tattoo with india ink for identification of colonic lesions. Surg Endosc. 1999;13(4):397-400.

14. Arteaga-Gonzalez I, Martin-Malagon A, Fernandez EM, Arranz-Duran J, Parra-Blanco A, Nicolas-Perez D, Quintero-Carrion E, et al. The use of preoperative endoscopic tattooing in laparoscopic colorectal cancer surgery for endoscopically advanced tumors: a prospective comparative clinical study. World J Surg. 2006;30(4):605-611.

15. Shaffer RT, Francis JM, Carrougher JG, Root SS, Angueira CE, Szyjkowski R, Kadakia SC. India ink tattooing in the esophagus. Gastrointest Endosc. 1998;47(3):257-260.

16. Sun L, Si J, Chen S, Liu W, Zhao L, Wang L. The establishment and clinical appliance of technique of mucosa marking targeting biopsy. Hepatogastroenterology. 2009;56(89):59-62.

17. Feingold DL, Addona T, Forde KA, Arnell TD, Carter JJ, Huang EH, Whelan RL. Safety and reliability of tattooing colorectal neoplasms prior to laparoscopic resection. J Gastrointest Surg. 2004;8(5):543-546.

18. Askin MP, Waye JD, Fiedler L, Harpaz N. Tattoo of colonic neoplasms in 113 patients with a new sterile carbon compound. Gastrointest Endosc. 2002;56(3):339-342.

19. Park JW, Sohn DK, Hong CW, Han KS, Choi DH, Chang HJ, Lim SB, et al. The usefulness of preoperative colonoscopic tattooing using a saline test injection method with prepackaged sterile India ink for localization in laparoscopic colorectal surgery. Surg Endosc. 2008;22(2):501505.

20. Alva S, Abir F, Tran DD. Laparoscopic gastric wedge resection for Dieulafoy's disease following preoperative endoscopic localization with India ink and endoscopic clips. JSLS. 2006;10(2):244-246.

21. Hoffman A, Kunert A, Lahat A, Volkov A, Zmora O, Rosin D. Laparoscopic resection of gastric Dieulafoy lesion following preoperative tattooing. Isr Med Assoc J. 2011;13(3):187-188.

22. Allam ME, Mehta D, Zelen J, Fogler R. Posterior wall gastric leiomyoma: endoscopic tattooing facilitates laparoscopic resection. JSLS. 1998;2(1):83-84.

23. Kohno M, Ikawa H, Fukumoto H, Okamoto S, Masuyama H, Konuma K. Usefulness of endoscopic marking for determining the location of transanal endorectal pullthrough in the treatment of Hirschsprung's disease. Pediatr Surg Int. 2005;21(11):873-877.

24. Salomon P, Berner JS, Waye JD. Endoscopic India ink injection: a method for preparation, sterilization, and ad- 
ministration. Gastrointest Endosc. 1993;39(6):803-805.

25. Cappell MS, Courtney JT, Amin M. Black macular patches on parietal peritoneum and other extraintestinal sites from intraperitoneal spillage and spread of India ink from preoperative endoscopic tattooing: an endoscopic, surgical, gross pathologic, and microscopic study. Dig Dis Sci. 2010;55(9):2599-2605.

26. Mitrani-Boyle C, Romero-Lagarza A, Shuchleib S. Hallazgos patologicos sorpresivos despues de tatuaje endoscopico. Endoscopia. 2011;23(2):70-72.

27. Hellmig S, Stuber E, Kiehne K, Folsch UR. Unusual course of colonic tattooing with India ink. Surg Endosc. 2003;17(3):521.

28. Del Rio P, Dell'Abate P. Complication of an endoscopic tattoo. Endoscopy. 2003;35(7):638.

29. Tutticci N, Cameron D, Croese J, Roche E. Peritoneal deposits with carbon pigmentation associated with endoscopic submucosal tattooing of a rectal cancer. Endoscopy. 2010;42(Suppl 2):E136.

30. Park SI, Genta RS, Romeo DP, Weesner RE. Colonic abscess and focal peritonitis secondary to india ink tattooing of the colon. Gastrointest Endosc. 1991;37(1):68-71.

31. Bang CS, Kim YS, Baik GH, Han SH. Colonic abscess induced by India ink tattooing. Korean J Gastroenterol. 2014;64(1):45-48.

32. Alba LM, Pandya PK, Clarkston WK. Rectus muscle abscess associated with endoscopic tattooing of the colon with India ink. Gastrointest Endosc. 2000;52(4):557-558.

33. Singh S, Arif A, Fox C, Basnyat P. Complication after pre-operative India ink tattooing in a colonic lesion. Dig
Surg. 2006;23(5-6):303.

34. Moss A, Bourke MJ, Pathmanathan N. Safety of colonic tattoo with sterile carbon particle suspension: a proposed guideline with illustrative cases. Gastrointest Endosc. 2011;74(1):214-218.

35. Marques I, Lagos AC, Pinto A, Neves BC. Rectal intramural hematoma: a rare complication of endoscopic tattooing. Gastrointest Endosc. 2011;73(2):366-367.

36. Dell'Abate P, Iosca A, Galimberti A, Piccolo P, Soliani P, Foggi E. Endoscopic preoperative colonic tattooing: a clinical and surgical complication. Endoscopy. 1999;31(3):271-273.

37. Coman E, Brandt LJ, Brenner S, Frank M, Sablay B, Bennett B. Fat necrosis and inflammatory pseudotumor due to endoscopic tattooing of the colon with india ink. Gastrointest Endosc. 1991;37(1):65-68.

38. Gopal DV, Morava-Protzner I, Miller HA, Hemphill DJ. Idiopathic inflammatory bowel disease associated with colonic tattooing with india ink preparation - case report and review of literature. Gastrointest Endosc. 1999;49(5):636-639.

39. Bahadursingh AM, Driver M, Koenig CL, Longo WE. Inadvertent transmural India ink tattooing simulating intestinal infarction. Am J Surg. 2003;185(1):88-89.

40. Gianom D, Hollinger A, Wirth HP. [Intestinal perforation after preoperative colonic tattooing with India ink]. Swiss Surg. 2003;9(6):307-310.

41. Chen N, Lamba R, Lee J, Lall C. Mesenteric air embolism following enteroscopic small bowel tattooing procedure. J Clin Imaging Sci. 2012;2:86. 